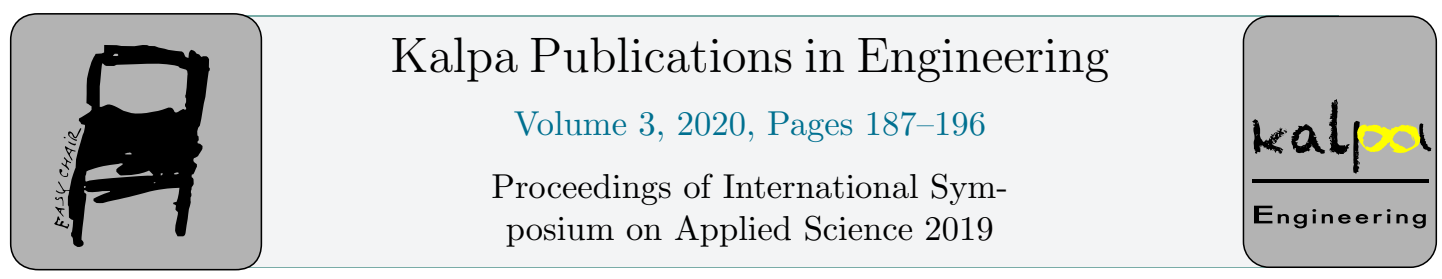

\title{
The Microstructure Of Liquid Lithium Silicate Under Pressure
}

\author{
Duc Quynh Truong ${ }^{1}$, Thanh Dung Tran², Van Dung Mai ${ }^{2}$, The Vinh $\mathrm{Le}^{3}$ \\ ${ }^{1}$ Ho Chi Minh City University of Transport, Ho Chi Minh City, Vietnam \\ ${ }^{2}$ Thu Dau Mot University, Binh Duong Province, VietNam \\ ${ }^{3}$ Ton Duc Thang University, Ho Chi Minh City, Vietnam \\ tdquynhhtegmail.com
}

\begin{abstract}
The microstructural characteristics of liquid lithium silicate $\left(\mathrm{Li}_{2} \mathrm{SiO}_{3}\right)$ are investigated through molecular dynamics simulation using the Born-Mayer pairwise potentials. The simulations were performed on the systems with up to 2025 atoms (consist of $750 \mathrm{Li}, 375$ $\mathrm{Si}$, and $1125 \mathrm{O}$ atoms) at $3200 \mathrm{~K}$ in the $0-30 \mathrm{GPa}$ pressure range. The microstructure of liquid $\mathrm{Li}_{2} \mathrm{SiO}_{3}$ is analyzed via pair radial distribution functions (PRDFs), coordination distributions, angular distributions. The results show that the structure of the liquid lithium silicate consists of the basic structural units $\mathrm{TO}_{4}(\mathrm{~T}=\mathrm{Li}, \mathrm{Si})$ at ambient pressure, and these units decrease as the pressure increases. Besides, the shape and size of the basic structural units are slightly dependent on pressure. Calculations also indicate that calculated data agree well with the experimental ones.
\end{abstract}

\section{Introduction}

Liquid silicate materials have been studied by various experimental techniques such as nuclear magnetic resonance spectroscopy, infrared spectrum, Raman spectrum, and X-ray scattering [1, 2]. These studies mainly focus on analyzing the local structure of cationic atoms. Research results have shown that when the component of $\mathrm{MOx}(\mathrm{M}: \mathrm{Al}, \mathrm{Pb}, \mathrm{Mg} . .$.$) increases, the rate of high-proportional$ structural units increases.

It means that there is a change of structural units from the tetrahedral structure to the octahedral structure under the influence of the MOx component. Research results [3-5] show that at low pressure, the structure of the main materials is $\mathrm{SiO} 4, \mathrm{AlO} 3, \mathrm{AlO} 4$, and $\mathrm{AlO}$. When the pressure increases, the structural units $\mathrm{SiO} 4, \mathrm{AlO} 3$, and $\mathrm{AlO} 4$ decrease while the structural units $\mathrm{SiO}$, $\mathrm{SiO}$, AlO5, and $\mathrm{AlO} 6$ increase. The results of this study are entirely consistent with previous simulation and experimental studies.

Experimental studies and simulation studies also show the existence of the basic structure units TOx ( $\mathrm{T}$ is $\mathrm{Al}$ and $\mathrm{Si} ; \mathrm{x}=4,5,6$ ) in the liquid and amorphous model of $\mathrm{Al}_{2} \mathrm{O}_{3} \cdot 2 \mathrm{SiO}_{2}$. The proportion of these 
structural units varies significantly when the pressure changes, but their sizes and shapes vary little. At the same time, rich cationic regions of $\mathrm{Al}$ and $\mathrm{Si}$ are also found. This may cause a strong impact on microphase separation [6-10].

For lithium ceramics, which are a promising material, is considered a shaping material because of its good Triti solubility, chemical, and mechanical thermal stability at high temperatures and convenience in irradiation [11-13]. However, the microstructure of Lithiumsilicate is limited. In this paper, we focus on clarifying the microstructure of this material by using molecular dynamics (MD) simulation and visualizing simulation data under the influence of pressure.

\section{Calculation Method}

The model $\mathrm{Li}_{2} \mathrm{O} . \mathrm{SiO}_{2}$ consist of 2250 atoms ( $375 \mathrm{Si}, 750 \mathrm{Li}$, and $1125 \mathrm{O}$ atoms) was constructed by means molecular dynamics simulation with recirculating boundary condition and the potential interaction Born-Mayer,

$$
\mathrm{U}_{\mathrm{ij}}=\frac{\mathrm{q}_{\mathrm{i}} \mathrm{q}_{\mathrm{j}}}{\mathrm{r}_{\mathrm{ij}}}+\mathrm{A}_{\mathrm{ij}} \exp \left(-\mathrm{B}_{\mathrm{ij}} \mathrm{r}_{\mathrm{ij}}\right)
$$

with $\mathrm{i}, \mathrm{j}=\mathrm{Li}, \mathrm{Si}, \mathrm{O}, \mathrm{r}$ is the interaction distance, the potential coefficients Aij and Bij as table 1 .

The initial configuration is obtained by randomly placing all atoms in a simulation box. This sample is equilibrated the temperature of $6000 \mathrm{~K}$ for $50.000 \mathrm{MD}$ steps. After that, this sample was cooled down to the temperature of $3200 \mathrm{~K}$. In steady-state with $0 \mathrm{GPa}$ pressure and $3200 \mathrm{~K}$ temperature, the reliability of the equilibrium model (EM) was checked by comparing the calculated partial radial distribution functions (PRDFs) with one of the published works for both experiment and simulation. Models at a pressure of $5 \mathrm{GPa}, 10 \mathrm{GPa}, 15 \mathrm{GPa}, 20 \mathrm{GPa}, 25 \mathrm{GPa}$, and $30 \mathrm{GPa}$ are obtained by compressing the EM at $0 \mathrm{GPa}$ pressure. In each of these models will be relaxed after 10,000 simulation steps in NPT mode. To improve the statistics of the measure, the characteristics of the parameters are computed by averaging over 1000 configurations separated by $10 \mathrm{MD}$ simulation steps. Potential coefficients are referenced from research [13].

To illustrate the compression process of the liquid Lithiumsilicate material model, we visualize simulation data with VESTA software $[14,15]$. Based on the calculated data, we visualize the research model at two different pressures to better describe the structure of the research models.

\begin{tabular}{ccccccc}
\hline $\begin{array}{c}\text { Potential } \\
\text { coefficient }\end{array}$ & O-O & O-Si & Si-Si & O-Li & Si-Li & Li-Li \\
\hline $\mathrm{A}_{\mathrm{ij}} / \mathrm{eV}$ & 1759 & 10734 & $8.734 \times 10^{8}$ & 2391 & 239343 & 6720 \\
$\mathrm{~B}_{\mathrm{ij}} / \AA^{-1}$ & 2.8464 & 4.7959 & 15.2207 & 4.0182 & 9.4286 & 6.82 \\
\hline
\end{tabular}

Table 1: Interactive potential coefficient [13]

\section{Results And Discussion}

The local microstructure of liquid Lithiumsilicate materials was clarified based on analysis: radial distribution function, coordination distribution number, bond angle distribution, bond length distribution, and visual simulation data with VESTA software. 


\subsection{Radial distribution function $\mathrm{g}(\mathrm{r})$}

Figure 1 shows the radial distribution function of pairs of atoms in liquid Lithiumsilicate materials under pressure from $0 \mathrm{GPa}$ to $30 \mathrm{GPa}$. It can be seen that the position of the first peak of the radial distribution function of the atomic pairs of $\mathrm{Si}-\mathrm{Si}, \mathrm{Si}-\mathrm{O}$, and $\mathrm{O}-\mathrm{Li}$ do not change when the pressure increases, while the height of the first peak of the pairs $\mathrm{Si}-\mathrm{Si}, \mathrm{O}-\mathrm{O}, \mathrm{Li}-\mathrm{Li}$ and $\mathrm{Si}-\mathrm{O}$ decrease when the pressure increases.

The opposite for atomic pairs of $\mathrm{Si}-\mathrm{Li}$ and $\mathrm{O}-\mathrm{Li}$, these pairs have the first peaks height increase when the pressure increases and the first peaks position of O-O, $\mathrm{Si}-\mathrm{Li}$ and $\mathrm{Si}-\mathrm{Li}$ shift to the left when the pressure increases, particularly atomic pair of $\mathrm{Si}$-Li with the first peak position at the pressure of 5 GPa sharply shifts to the left. The first peaks position of the atomic pairs of O-O, Si-Si, Si-O, and Li-O at $0 \mathrm{GPa}$ correspond to $2.66 \AA ; 3.08 \AA ; 1.62 \AA ; 1.96 \AA$ (Table 3.1 ), these values perfectly match the results of experimental X-ray diffraction and simulation results [11-13]
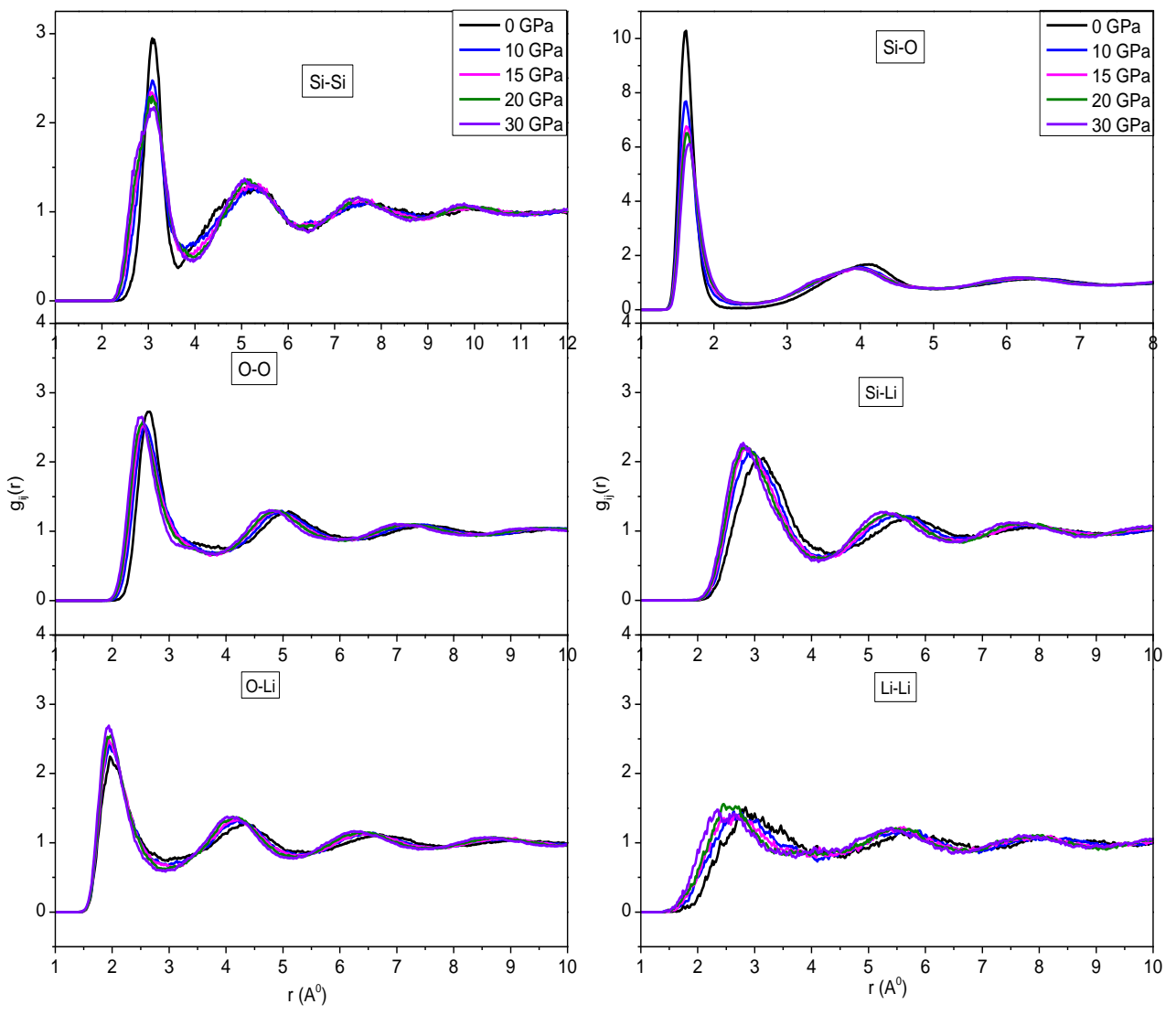

Figure 1: Radial distribution of $\mathrm{Li}_{2} \mathrm{O} . \mathrm{SiO}_{2}$ pairs at different pressures. 


\subsection{Distribution of coordination number}

Figure 2a shows the distribution of coordination numbers of $\mathrm{Si}$ and $\mathrm{Li}$ atoms under pressure (scale of TOx structural units in the model: $\mathrm{x}=3,4,5,6)$. It can be seen that at low pressure most $\mathrm{Si}$ atoms have a coordination number of 4 to form $\mathrm{SiO} 4$ tetrahedral structure and account for about $93 \%$, while the percentage of SiO5 structural unit is small and that of $\mathrm{SiO} 6$ is almost nonexistent. When the pressure increases, the percentage of $\mathrm{SiO} 4$ structural unit decreases sharply to about $7 \%$ at a pressure of $30 \mathrm{GPa}$, while this ratio of $\mathrm{SiO} 5$ and $\mathrm{SiO} 6$ increases. In particular, the $\mathrm{SiO} 5$ structural unit ratio reaches the maximum value at $15 \mathrm{GPa}$ to $25 \mathrm{GPa}$, accounting for about $52 \%$, then this ratio decreases with increasing pressure. The percentage of $\mathrm{SiO} 6$ structural unit increases linearly with pressure and has a peak at about $48 \%$ at a pressure of $30 \mathrm{GPa}$. Meanwhile, the ratio of SiO3 structural unit hardly appears in the model at all pressures.

Figure $2 \mathrm{~b}$ illustrates the coordinate distribution in the $\mathrm{LiO}_{\mathrm{x}}$ structural units into pressure (with $\mathrm{x}=$ $3,4,5,6)$. Accordingly, the percentage of $\mathrm{LiO} 3$ and $\mathrm{LiO} 4$ structural units at $0 \mathrm{GPa}$ accounts for about $32 \%$ and $40 \%$ respectively. These ratios decrease when the pressure increases from $0 \mathrm{GPa}$ to $30 \mathrm{GPa}$. According to Figure $3.2 \mathrm{~b}$ and Table 3.4, when the pressure increases from $0 \mathrm{GPa}$ to $30 \mathrm{GPa}$, the percentage of $\mathrm{LiO}_{5}$ structural unit increases and reaches a peak of about $45 \%$ at a pressure of $10 \mathrm{GPa}$ and then decreases. Meanwhile, the ratio of $\mathrm{LiO}_{6}$ structural unit increases sharply and reaches the maximum value of about $47 \%$ at a pressure of $30 \mathrm{GPa}$. These results are consistent with previous experimental and simulation results [11-13].

Thus, at low pressure, the ratio of the low number of coordination units counts the majority, while at high pressure the ratio of the high number of that dominates. This trend has been found in previous studies of liquid silicate materials of Lead and Aluminum metals. [3, 4, 9]
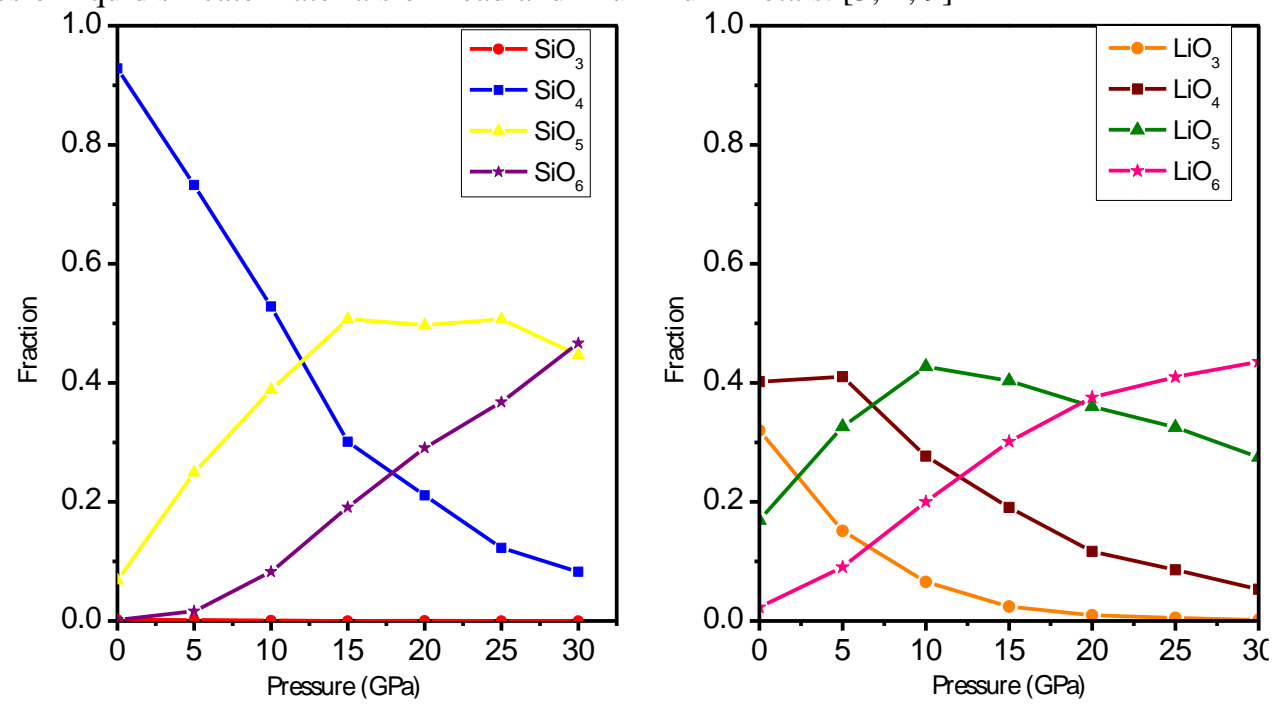

Figure 2: a) Distribution of coordination units in $\mathrm{SiO}_{x}$ and b) the $\mathrm{LiO}_{x}$

By visualizing simulation data at $0 \mathrm{GPa}$ pressure, the results show that the structure of the majority material model is tetrahedral. Figure 3 and Figure 4 gives more clearly the above analysis in which the tetrahedral structure occupies a majority in the model at low pressure. 


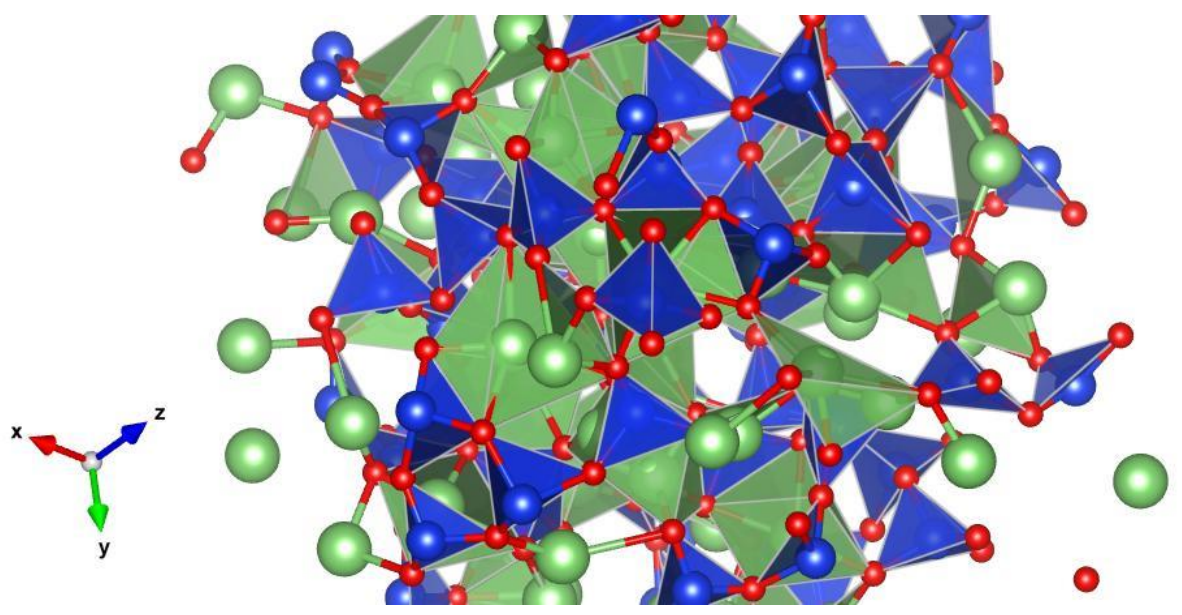

Figure 3: Tetrahedral structure of the material at $0 \mathrm{Gpa}$ (Si: dark blue, O: red, Li: blue)
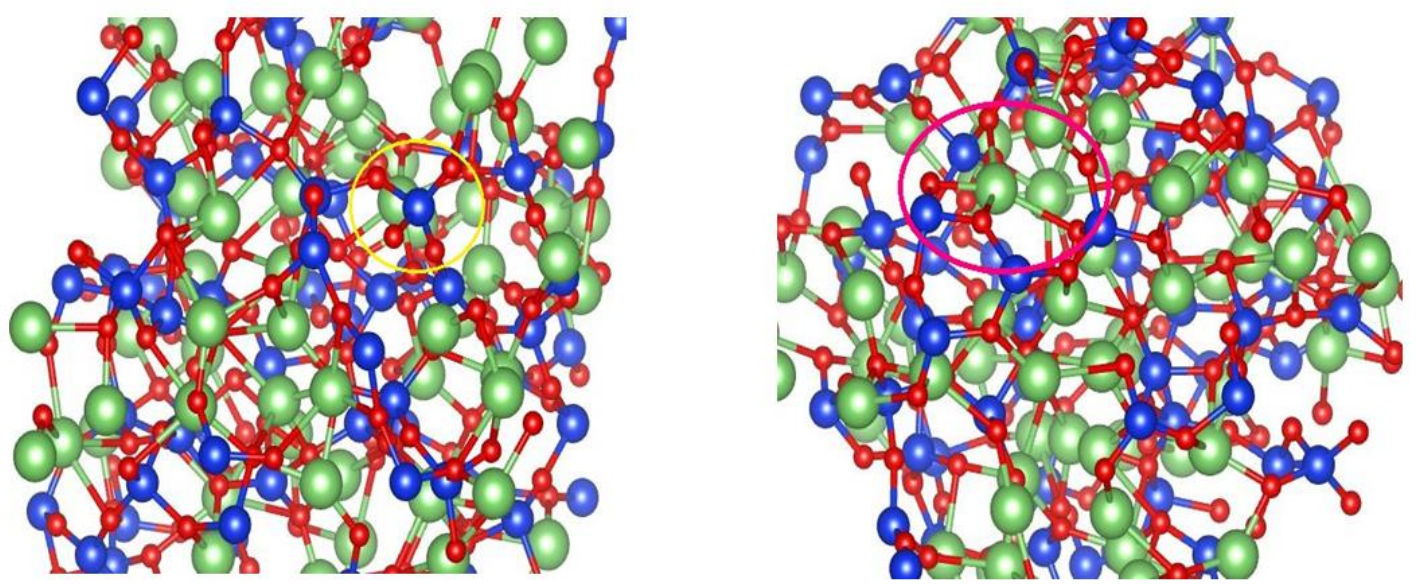

Figure 4: Tetrahedral structure of $\mathrm{LiO}_{4}$ and $\mathrm{SiO}_{4}$ at $0 \mathrm{GPa}$

\subsection{Bond angle distribution}

Figure 5 shows the bond angle distribution of $\mathrm{SiOx}$ structure units at different pressures. For the $\mathrm{SiO}_{4}$ structural unit, when the pressure increases from $0 \mathrm{GPa}$ to $30 \mathrm{GPa}$, the first peak height of the associated angle distribution decreases. At $0 \mathrm{GPa}$ pressure, the position of the first peak is at $98^{\circ}$, this position moves slightly to the left when the pressure increases, meanwhile the angle with the greatest probability drops. In the opposite trend for $\mathrm{SiO}_{5}$ and $\mathrm{SiO}_{6}$ structural units, the height of the first peak of the bond angle distribution tends to increase when the pressure increases. The position of the first peak of the structural unit $\mathrm{SiO}_{5}$ is $90^{\circ}$ and of the structural unit $\mathrm{SiO}_{6}$ is $98^{\circ}$, these positions move slightly to the left. For structural units $\mathrm{SiO}_{5}$ and $\mathrm{SiO}_{6}$, apart from the first peaks, there are also the second peaks at the position of $160^{\circ}$. These calculations are consistent with previous studies [12].

Figure 6 illustrates that all heights of the first peak of the bond angle distribution of $\mathrm{LiO}_{3}, \mathrm{LiO}_{4}$, $\mathrm{LiO}_{5}$, and $\mathrm{LiO}_{6}$ units have a small rate, less than $10 \%$. For the structural unit $\mathrm{LiO}_{4}$, the height and position of the first peak do not change when the pressure increases, its peak position is at $100^{0}$. This value is consistent with the results researched that the height and position of the first peak change very slightly when the pressure increases. Structural units of $\mathrm{LiO}_{5}$ and $\mathrm{LiO}_{6}$ have a peek at position $75^{\circ}$, this 
position changes slightly when the pressure increasing from $0 \mathrm{GPa}$ to $30 \mathrm{GPa}$. The first peak of the bond angle distribution in the structural unit $\mathrm{LiO}_{6}$ moves to the right when the pressure increases. These results are also consistent with the results of previous studies [12].

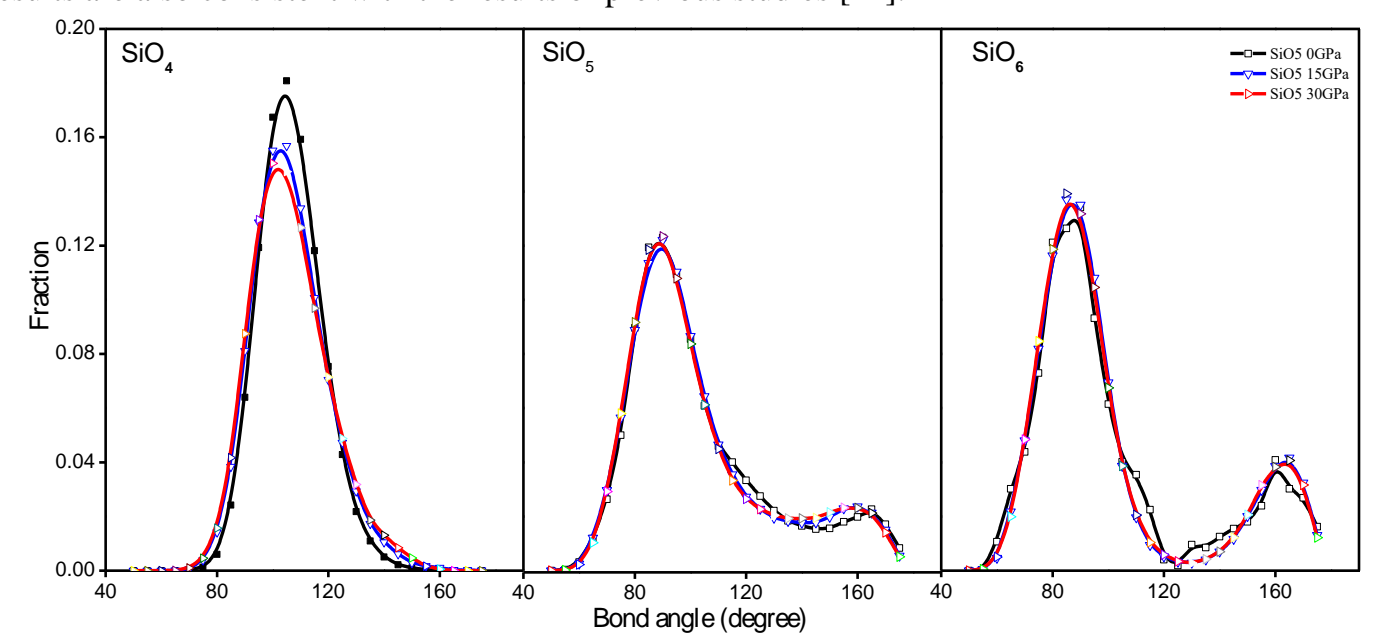

Figure 5: Distribution of the bond angle in $\mathrm{SiO}_{\mathrm{x}}$

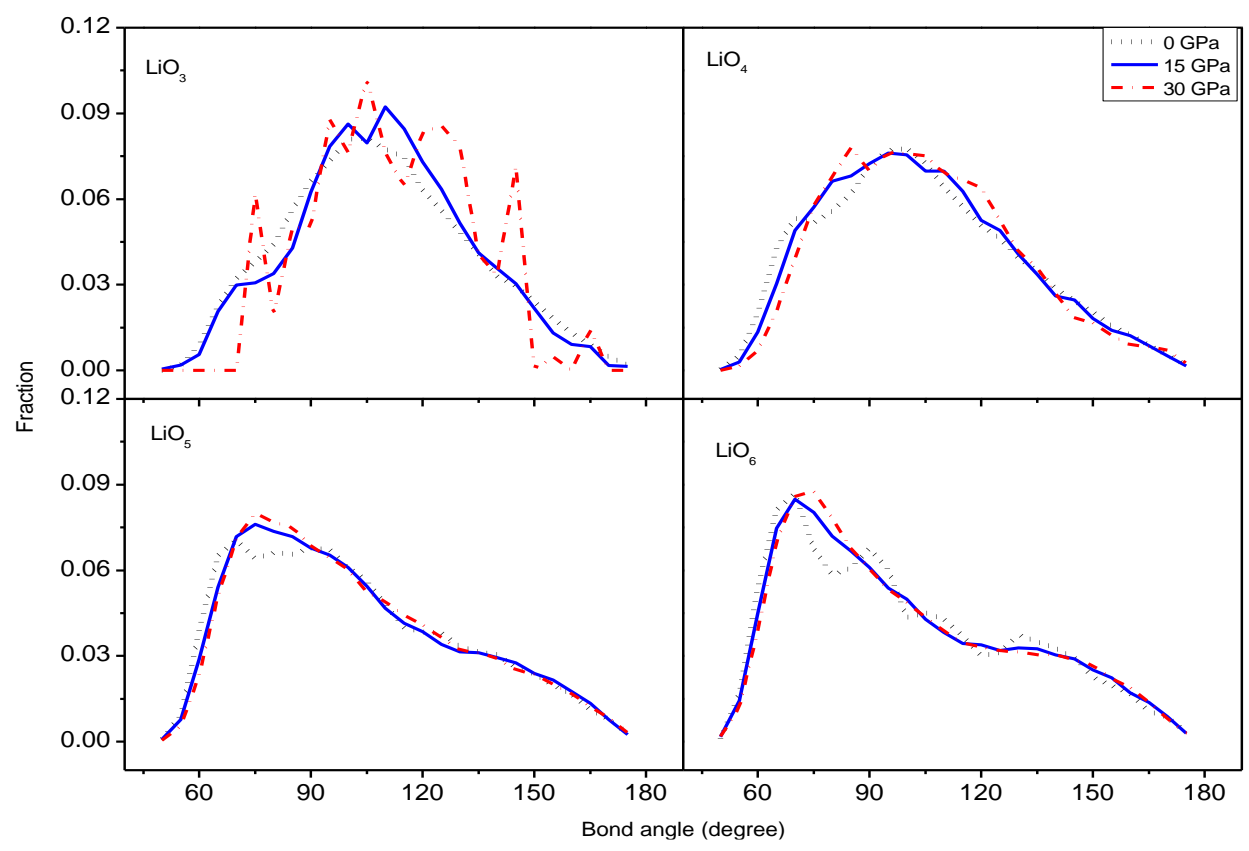

Figure 6: Distribution of the bond angle in the $\mathrm{LiO}_{\mathrm{x}}$

\subsection{Bond length distribution}

Figure 7 gives that the first peak height of the bond length distribution of the structural units $\mathrm{LiOx}$ decreases when the pressure increases. For the bond length distribution of structural unit $\mathrm{LiO}_{4}$, the first peak position is $2.0 \AA$ at $0 \mathrm{GPa}$ and this value is $1.8 \AA$ at $30 \mathrm{GPa}$, these mean that under pressure the bond length of atoms reduces. This trend is also true for structural units of $\mathrm{LiO}_{4}, \mathrm{LiO}_{4}, \mathrm{LiO}_{5}$, and $\mathrm{LiO}_{6}$, 
but the height of the first peak of the bond length distributions of these structural units is small. Thus, under pressure, the spatial volume of the structural units decreases because the distance between the atoms decreases.

Figure 8 shows that the first peak height of the bond length distribution of structural units $\mathrm{SiOx}$ increases as the pressure increases. For the bond length distribution of the structural unit $\mathrm{SiO}_{3}$, the first peak position is $1.65 \AA$ at $0 \mathrm{GPa}$ pressure and this position is $1.5 \AA$ at $30 \mathrm{GPa}$ pressure, meaning the bond length of atoms reduces when pressure increases, about $9 \%$. This trend is also true for structural units $\mathrm{SiO}_{4}, \mathrm{SiO}_{5}$, and $\mathrm{SiO}_{6}$. Under pressure, the liquid is condensed due to reducing distance between the atoms. This trend has been found for the previously published materials as Aluminosilicate and Leadsilicate $[3,4,9]$.

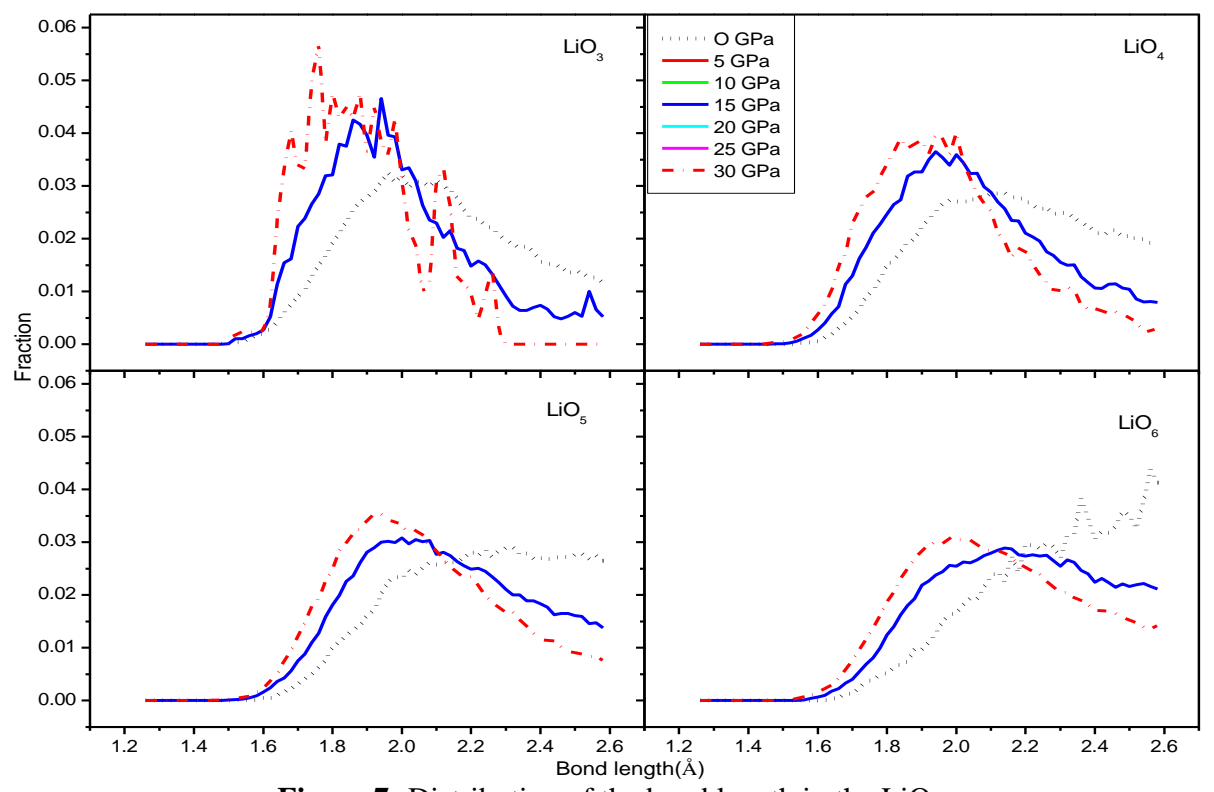

Figure 7: Distribution of the bond length in the $\mathrm{LiO}_{\mathrm{x}}$ 


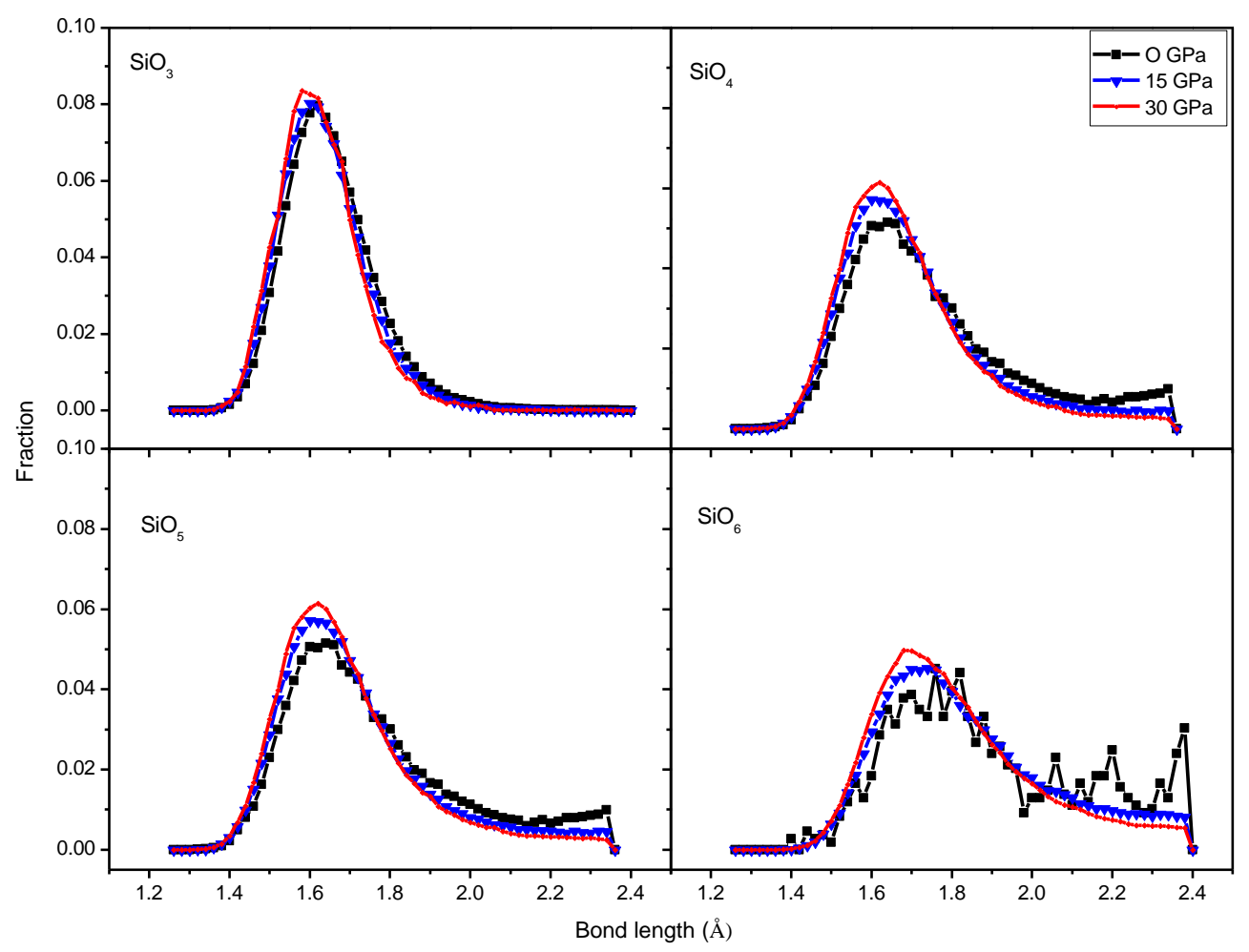

Figure 8: Distribution of the bond length in $\mathrm{SiO}_{\mathrm{x}}$

\subsection{Visualize simulation data}

Figure 3.9a shows that, at $0 \mathrm{GPa}$ pressure, the model appears many space volumes where there are no atoms, this is the concept of "void" mentioned in many simulation studies which were published earlier. While the higher pressure at $30 \mathrm{GPa}$, the amount of free space almost disappears (Figure 3.9b), which means when the pressure increases the structure of the model becomes more uniform. There are always high density and low-density areas in the material model, and finding these areas is very important. The issue of heterogeneous structures in silicate material systems is being studied a lot, but there are still many unanswered questions. 

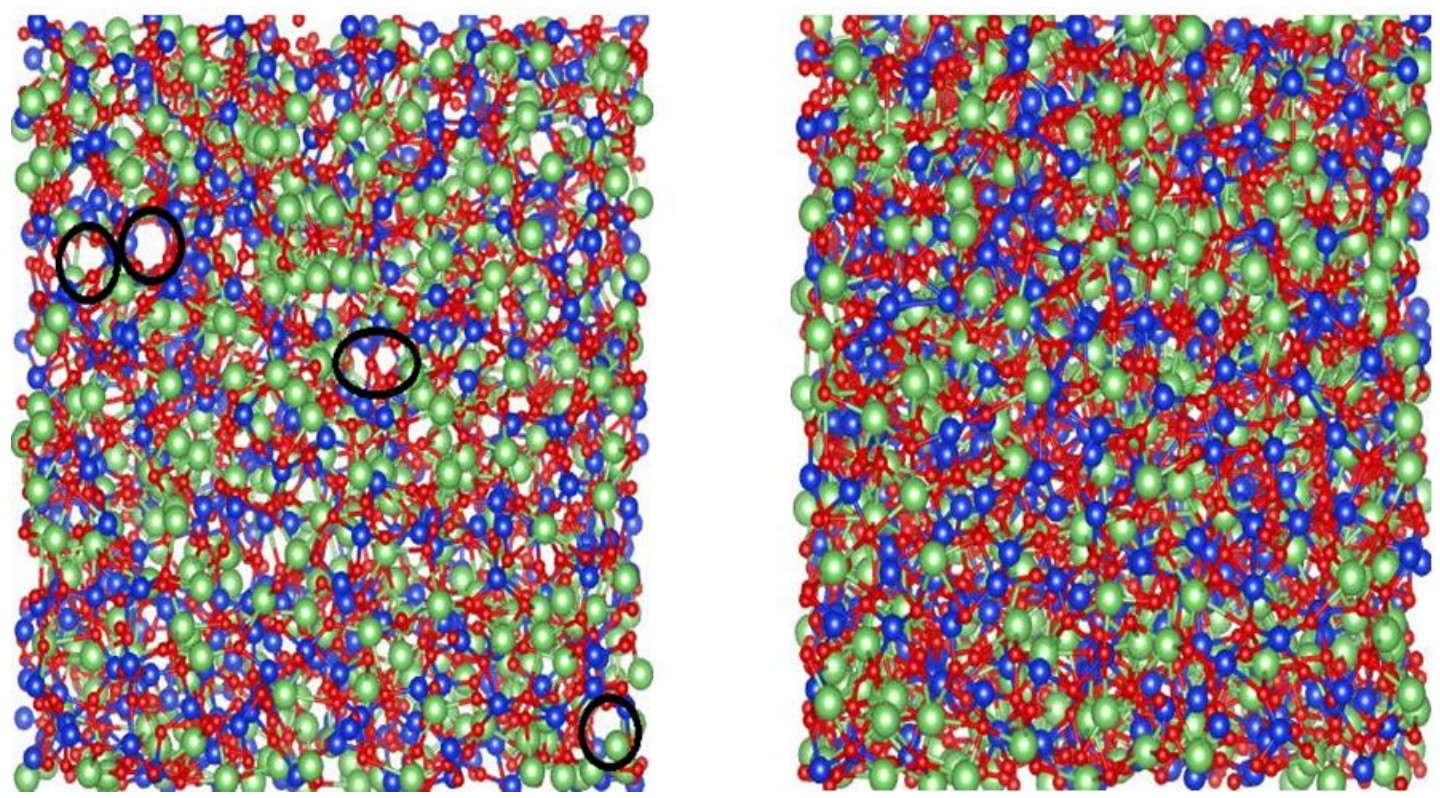

Figure 9: Model of $\mathrm{Li}_{2} \mathrm{O} \cdot \mathrm{SiO}_{2}$ material a) $0 \mathrm{GPa}$; b) $30 \mathrm{GPa}$

\section{Conclusion}

There are 8 models of $\mathrm{Li}_{2} \mathrm{SiO}_{3}$ that have been built at different pressures from $0 \mathrm{GPa}$ to $30 \mathrm{GPa}$, which have PRDFs agree with experimental and calculated results. These models can be used for studying other physical properties.

The research results show that low pressure in the model mainly contains tetrahedral structural units of $\mathrm{SiO}_{4}(93 \%)$ and $\mathrm{LiO}_{4}$, while at high pressure mainly contains structural units are $\mathrm{SiO}_{5}, \mathrm{SiO}_{6}, \mathrm{LiO}_{5}$, and $\mathrm{SiO}_{6}$. Thus, there is a structural change when the pressure increases. The bond length between atoms decreases significantly when the pressure increases, which causes the shape of the structural units to change. The simulation results are visualized by VESTA software show that when the pressure increases the structure of the material is more homogeneous. The research results are in good agreement with the results of experimental studies and simulations which were previously published.

\section{References}

[1] H. Morikawa, S.I. Miwa, M.Miyake, F. Marumo (1982), "Structural analysis of $\mathrm{SiO}_{2}-\mathrm{Al}_{2} \mathrm{O}_{3}$ ”, J. Am. Ceram. Soc. 65, 78.

[2] M. Okuno, N. Zotov, M. Schmucker, and H. Schneider (2005), "Structure of $\mathrm{SiO}_{2-}$ $\mathrm{Al}_{2} \mathrm{O}_{3}$ glasses: Combined X-ray diffraction, IR and Raman studies", J. Non-Cryst. Solids 351, 1032.

[3] Mai, L. T., Nguyen, Y. V., Nguyen, H. V., \& Pham, H. K. (2017). Visualization-based analysis of structure and dynamics of liquid aluminosilicate under compression. Physics and Chemistry of Liquids, 55(1), 62-84.

[4] N.V. Hong, N.V. Yen, M.T. Lan, and P.K. Hung (2014), Coordination and polyamorphism of aluminum silicate under high pressure: insight from analysis and visualization of molecular dynamics data, Can. J. Phys. 92: 1573-1580. 
[5] Yen, N. V., Hong, N. V., Hung, P. K., \& Huy, N. V. (2015). Structural heterogeneity and dynamics in liquid $\mathrm{PbSiO} 3$ : insight from analysis and visualization of molecular dynamics data. Materials Research Express, 2(6), 065201.

[6] Mysen, B. O., Virgo, D., \& Seifert, F. A. (1982). The structure of silicate melts implications for the chemical and physical properties of natural magma. Reviews of Geophysics, 20(3), 353-383.

[7] Winkler, A., Horbach, J., Kob, W., et al, "Structure and diffusion in amorphous aluminum silicate A molecular dynamics computer simulation”, J. Chem. Physic 120, pp.384-393, 2004.

[8] Pfleiderer, P., Horbach, J., \& Binder, K, "Structure and transport properties of amorphous aluminum silicates: computer simulation studies", Chemical Geology, 229(1-3), 186-197, 2006.

[9] Van Hoang, V, "Composition dependence of static and dynamic heterogeneities in simulated liquid aluminum silicates”, Physical Review B, 75 (17), 174202, 2007.

[10] Hoang, V.V, "Dynamical heterogeneity and diffusion in high-density $\mathrm{Al}_{2} \mathrm{O}_{3} .2 \mathrm{SiO}_{2}$ melts", Physica B, 400, 278-286, 2007.

[11] Waseda, Y., \& Suito, H. (1977). Structure of molten alkali metal silicates. Trans. Iron Steel Inst. Jpn., 17(2), 82-91.)

[12] Habasaki, J., \& Okada, I. (1992). Molecular dynamics study of Li2SiO3 in the liquid and glassy states. Molecular simulation, 8(3-5), 179-195.).

[13] Banhatti, R. D., \& Heuer, A. (2001). Structure and dynamics of lithium silicate melt: molecular dynamics simulations. Physical Chemistry Chemical Physics, 3(23), 5104-5108.

[14] Heydon, A., Levin, R., Mann, T., \& Yu, Y. (2001). The Vesta approach to software configuration management. Compaq. Systems Research Center [SRC].

[15] Momma, K., \& Izumi, F. (2011). VESTA 3 for three-dimensional visualization of crystal, volumetric, and morphology data. Journal of applied crystallography, 44(6), 1272-1276. 